\title{
Chinese Teacher's Beliefs and Strategies Towards Preschool Children With Different Shyness Levels*
}

\author{
Wu YunPeng, Chen \\ YingMin \\ Shandong Normal \\ University, Ji'nan, China
}

\author{
Wu JianFen \\ Hangzhou Normal \\ University, \\ Hangzhou, China
}

\author{
Han PiGuo \\ Heze University, \\ Heze, China
}

\author{
Gao FengQiang \\ Shandong Normal \\ University, Ji’nan, China
}

The current study aimed to investigate teacher's beliefs and strategies regarding three hypothetical behaved (shy and silent, average behavior, exuberant and talkative) children by investigating 216 kindergarten teachers with questionnaires. It also aimed to explore whether the beliefs and strategies varied among teachers with different shyness levels as well as children with different genders. The results indicated that: (1) The main effect of children behavior was significant. In the aspect of teacher's beliefs, they rated the language and academic abilities as well as the excellence level of shy children as the lowest among three types of children. The shy behavior was viewed as having the most negative influence of children development. Shy and exuberant was considered as unstable traits. The shy behavior was attributed to situational factors rather than personality. In the aspect of strategies, teachers were more likely to report shy behavior to others, and to apply monitoring strategy, social learning strategy and peer-focused strategy to shy children, whereas to apply high-power strategy to exuberant children; and (2) The teacher's beliefs and strategies varied among teachers with different shyness levels as well as towards children with different genders.

Keywords: preschool teacher, beliefs, strategies, shyness, preschool children

\section{Introduction}

The teachers' beliefs is the point of view that teachers hold and believe in the teaching situation and procedures, which is about the relevant elements such as teaching task, role of teacher, curriculum, student, leaning and so on, covering teachers' practical teaching experience and life experience, and constituting a interconnected system, thereby guiding teachers' thinking and behavior system (Pajares, 1992). Teachers' beliefs directly and indirectly influence children's social, emotional, and academic development. Teachers' general beliefs about child development not only influence their classroom decisions, but also influence their responses to specific child behaviors and overall teaching style. The teacher-child relationship showed

\footnotetext{
*Acknowledgments: This research was funded by projects of humanities and social sciences of the Ministry of Education of China (12YJC190004, 12YJC190009), by project of National Social Science Foundation of China (13BSH061) and Science and Technology Development Plan Project of Shandong province (2013GSF11802) and the Program for Excellent Young Teachers in Hangzhou Normal University (HNUEYT2011-01-002), Scientific Research Projects of Heze University in 2014 (XY14SK02), the Key Discipline Construction Program of 12th Five-year Plan of Shandong province (Developmental and Educational Psychology). Wu YunPeng, Ph.D. candidate, School of Psychology, Shandong Normal University. Chen YingMin, Ph.D., School of Psychology, Shandong Normal University.

Wu JianFen, Ph.D., School of Education, Hangzhou Normal University. Han PiGuo, M.A., Department of Preschool Education, Heze University. Gao FengQiang (Correspondence author), Ph.D., School of Psychology, Shandong Normal University. Email: gaofq_11@163.com.
} 
significant influence on shy children's school adjustments (Wu et al., in press). Meanwhile, teachers' more specific attitudes and beliefs toward specific students in their classrooms also affect this student's peer relationships (McAuliffe, Hubbard, \& Romano, 2009) and teacher-child relationships (Rudasill \& Rimm-Kaufman, 2009). Moreover, teachers' beliefs about children's social interaction characteristics may influence their inferences about other traits of this child, such as intelligence and academic skills. In current study, the teachers' belief refers the teachers' beliefs to the students, and the teachers' strategy refers to the countermeasures taken by the teacher to student behavior.

Preschool period of children corresponds to two phases of Eriksson's personality development theory, namely independence vs. shyness stage (1.5-3 years old) and initiative vs. guilt stage (3-5 years old). Shy and silent behavior and exuberant and talkative behavior are two extreme behaviors at this stage. Previous western studies have suggested that teachers hold different beliefs and strategies toward the two types of children (Coplan, Hughes, Bosacki, \& Rose-Krasnor, 2011). Shyness is the inhibition and anxiety when one facing novel social situations or strangers or perceived social evaluations, which mainly reflected in approach-avoidance conflict (Coplan \& Armer, 2007). The level of children's shyness is significantly associated with their class participation. Studies have found that there is a negative correlation between preschool children's shyness and class participation, including cooperation participation and independent participation (Valiente, Swanson, \& Lemery-Chalfant, 2012). Meanwhile, a survey on 9 to 13 years old children also discovered the negative correlation between shyness and academic participation (Hughes \& Coplan, 2010). Because class participation is an important part of classroom learning, the silent behavior of shy children may be viewed by teacher as unintelligent. At the same time, since the shy behaviors help to maintain classroom discipline, teachers sometimes even encourage such behaviors ( $\mathrm{Y} . \mathrm{Wu}$, Chen, $\mathrm{Yu}, \mathrm{J}$. Wu, \& Gao, 2014). However, some scholars expressed objection to the view that teachers should encourage children's shy behavior. Although the shy children do not disrupt the classroom order or bully and attack their peer, the potential "victim" of sustained shy behavior is the shy children themselves. Therefore, more and more preschool teachers begin to realize the negative influence of shyness, and intend to make efforts to shy behavior intervention. Thijs and colleagues reported that preschool teachers apply the social emotional support strategy (for example: encourage children playing with other children in the class) to help shy children in their class (Thijs, Koomen, \& Van Der Leij, 2006).

Outgoing children's shyness level is relatively lower, but their positive emotions and social interaction level are higher. They have a strong behavior tendency to participate in the activities, and they exhibit less fear or inhibited behaviors in the face of novel things and strangers (Fox, Henderson, Rubin, Calkins, \& Schmidt, 2001). One study indicated that teachers are apt to consider that talkative children have better language skills, and are more creative and more intelligent (Evans, 1996). Nevertheless, if the children are overly talkative and cannot appropriately control their feeling expression in class, they may get into trouble. For instance, exuberant and talkative children may interrupt the class teaching, thus they may need extra attentions from teachers. Some studies have demonstrated that actions like interrupting other's speech, speaking without turn, and dominating class discussions, are the symbols of be with high impulsivity, inattention and other externalizing behavior problems (Stifter, Putnam, \& Jahromi, 2008). In terms of strategy, western researches suggested that teachers are more likely to employ high power strategies like controlling, constraining, punishment strategy towards children with destructive and impulsive behaviors (Nucci \& Turiel, 2009). 


\section{The Current Study}

Studies in western setting have found that teachers take different beliefs and strategies to shy/quiet children and exuberant/talkative children (Coplan, Hughes, Bosacki, \& Rose-Krasnor, 2011). Our review of the literature did not reveal any studies that specifically explore this issue in China. As people's acceptance to shy behavior varies under different cultural backgrounds, and the impact of shyness on children's adaption is not the same (X. Chen, DeSouza, H. Chen, \& Wang, 2006), it is necessary to carry out the study on teachers' beliefs and attitudes towards children in different level of shyness in China.

In addition, children's gender and teachers' shyness level may affect teachers' strategies and beliefs. Although studies demonstrated that parents and children's acceptance for shy girls are higher than that for boys (Wu et al., 2014), yet this gender difference has not been tested in the teacher sample. Meanwhile, though there are some researches exploring the relationship between teachers' personality and behavior (Zhang, 2007), but studies on the connection between teachers' personality and beliefs have not been reported. Therefore, the current study attempts to investigate the teachers' briefs and strategies towards three kinds of children with different levels of social participation and verbal participation (shy/silence, average behavior, exuberant/talkative), and explore whether their briefs and strategies vary due to different child gender and teachers' shyness level.

\section{Method}

\section{Participants and Procedure}

By random sampling, current study investigated 232 kindergarten teachers located in three cities (Heze, Ji'nan, Qingdao) of Shandong Province. Valid questionnaires were received from 216 teachers (3 men, 213 women), with valid collection rate as $93.10 \%$. The average age of participants is $25.35 \pm 6.02$ years, and the average teaching experience is $2.92 \pm 4.50$ years. In terms of the marital status: single, $n=173$; married, $n=41$; other marital status, $n=2$. The distribution of education background as following: junior high school and below, $n=4$; senior high school or technical secondary school, $n=19$; junior school, $n=81$; university and above, $n=112$.

To avoid practice effect, the questionnaires are designed as two versions (i.e., boy/girl). Each questionnaire only investigates teachers' beliefs and strategies regarding three kinds of children of one gender. By random selection, every teacher only finished one version of the questionnaires. Finally, 111 boy-version and 105 girl-version questionnaires were collected. The demographic variables and shyness levels of the two teacher groups that assigned to complete these two visions of the questionnaires showed no significant differences.

\section{Measures}

Children behavior description texts. Teachers were asked to read three short paragraphs describing the following three kinds of children's behavior: shy and silent; average behavior; exuberant and talkative. Among these three descriptions, the language and social participation levels are generally increased, while their shyness level is generally reduced. The description texts have two versions as boy-vision and girl-vision, which are different only in names of characters and personal pronoun (he/she). These descriptions have been used in previous study (Coplan et al., 2011). The Chinese vision of the texts was translated by two psychology doctorial candidates. Professors in preschool education field were invited to review the texts which exhibited good content validity and face validity. The Latin square design was applied in the presentation order of three descriptions in the questionnaire to balance the possible order effect. 
Questionnaire of teacher's beliefs and strategies. This questionnaire includes the subscale of beliefs (five dimensions: behavior stability, personality-situation attribution, language and academic abilities, the intelligence level, negative consequences) and the subscale of strategies (5 dimensions: high-power strategy, social learning strategy, peer-focused strategy, indirect strategy, and report strategy). After reading one part of description, the teachers were asked to report their beliefs they hold to this hypothetical child with 5-point Likert scale (1-5). At the same time, teachers were asked to report the possibilities they would take to this behavior ranging from 1 ("Not likely at all") to 5 ("Very likely"). The questionnaire had a good reliability and validity in previous study (Coplan et al., 2011).

Shyness scale. The Chinese version of Cheek and Buss Shyness Scale is widely applied in China (Cheek \& Buss, 1999). It is a 13-item scale for measuring shyness level with a 5-point Likert scale (1-5). Four items (3, $6,9,12)$ are reverse scoring. The scores of all items summed up, with higher score represent the higher shyness level. This scale demonstrated good internal consistency coefficient $(\alpha=0.847)$ in current study.

Statistical analyses. The analyses were conducted with statistical software SPSS 16.0. Firstly, the teachers were divided into three groups according to their shyness score: (1) shy ( $n=54$, shyness scores in the top $25 \%$ of the sample); (2) average ( $n=108$, shyness scores in the middle $50 \%$ of the sample); (3) outgoing ( $n=54$, shyness scores in the bottom $25 \%$ of the sample). The three group teachers are no significant difference in demographic variables. Then, Pearson correlation analysis indicated that teachers' age, school age, and education level are not significant with teacher's beliefs and strategies for children, so we do not control these variables in the subsequent analysis. Taking teacher's beliefs and strategies as the dependent variable, the 2 (child gender: boys, girls) $\times 3$ (children's behavior: shy and silent, average, exuberant and talkative behavior) $\times 3$ teacher's shyness (shy, average, outgoing) mixed repeated-measures analyses of variance were conducted. The children behavior was viewed as within-subject variable, while teacher shyness and child gender as between-subject variables.

\section{Results}

\section{Teacher Beliefs}

Behavior stability. The main effect of child behavior was significant, $F(2,420)=81.97, p<0.001$, partial $\eta^{2}=0.281$. The main effect of child gender was significant, $F(1,210)=4.72, p<0.05$, partial $\eta^{2}=0.022$. The interaction of child behavior $\times$ teacher shyness was significant, $F(4,420)=2.90, p<0.05$, partial $\eta^{2}=0.027$. The interaction of child gender $\times$ teacher shyness was significant, $F(2,420)=4.27, p<0.05$, partial $\eta^{2}=0.020$. None of the two-way interactions (child behavior $\times$ child gender) or the three-way interactions (child behavior $\times$ teacher shyness $\times$ child gender) were significant.

Results from post hoc analyses indicated that teachers believed that the behaviors of average child would be significantly more stable than the exuberant/talkative child or shy child (see Table 1); and the behaviors of boys would be more stable than girls.

In terms of the two-way child behavior $\times$ teacher shyness interaction, results from follow-up simple effects analyses (see Figure 1) indicated that, for teachers with different shyness levels, there was no significant difference on their evaluation about the behavior stability of exuberant/talkative and average child. However, their evaluations for shy children showed a significant difference, $F(2,213)=5.80, p<0.01$. That is, compared with average teachers and shy teachers, outgoing teachers gave significantly lower evaluation for the stability of shy/quiet behavior.

With regard to the two-way child behavior $\times$ teacher shyness interaction, results from follow-up simple 
effects analyses (see Figure 2) indicated that, teacher's view on the stability of average showed no gender difference. However, their evaluation of that of shy child $(F(1,214)=15.09, p<0.001)$ and exuberant/talkative child $(F(1,124)=7.45, p<0.01)$ indicated gender differences. The post hoc analyses indicate that, for both shy child and talkative child, teachers were significantly more likely to report the stable of boys than girls.

Table 1

Means (and Standard Deviations) for Preschool Teachers' Strategies and Beliefs Toward Three Hypothetical Behavior Children $(n=426)$

\begin{tabular}{llll}
\hline & Shy/quite & Exuberant/talkative & Average \\
\hline Teacher beliefs & & & \\
Stability $^{1}$ & $2.65_{\mathrm{b}}(0.81)$ & $2.75_{\mathrm{b}}(0.78)$ & $3.55_{\mathrm{a}}(0.91)$ \\
Personality-situation $^{2}$ & $3.12_{\mathrm{a}}(0.78)$ & $2.79_{\mathrm{b}}(0.85)$ & $2.89_{\mathrm{b}}(0.80)$ \\
Academic-abilities $_{\text {Intelligence }}$ & $2.71_{\mathrm{c}}(0.67)$ & $3.68_{\mathrm{b}}(0.72)$ & $3.87_{\mathrm{a}}(0.77)$ \\
Negative consequences $_{\text {Teacher strategies }}$ & $3.31_{\mathrm{b}}(0.83)$ & $3.73_{\mathrm{a}}(0.86)$ & $3.86_{\mathrm{a}}(0.89)$ \\
High-powered & $3.75_{\mathrm{a}}(0.91)$ & $2.48_{\mathrm{b}}(0.76)$ & $1.92_{\mathrm{c}}(0.84)$ \\
Social learning & & & \\
Peer-focused & $2.44_{\mathrm{b}}(0.80)$ & $2.71_{\mathrm{a}}(0.82)$ & $1.67_{\mathrm{c}}(0.68)$ \\
Indirect & $4.30_{\mathrm{a}}(0.63)$ & $4.03_{\mathrm{b}}(0.80)$ & $3.78_{\mathrm{c}}(0.91)$ \\
Report & $4.23_{\mathrm{a}}(0.76)$ & $3.68_{\mathrm{b}}(0.87)$ & $3.44_{\mathrm{c}}(0.94)$ \\
\hline
\end{tabular}

Notes. ${ }^{1}$ Higher scores indicate greater stability; ${ }^{2}$ High scores indicate it is more due to the situation. Means in the same row with different subscripts differ significantly at the 0.05 level.

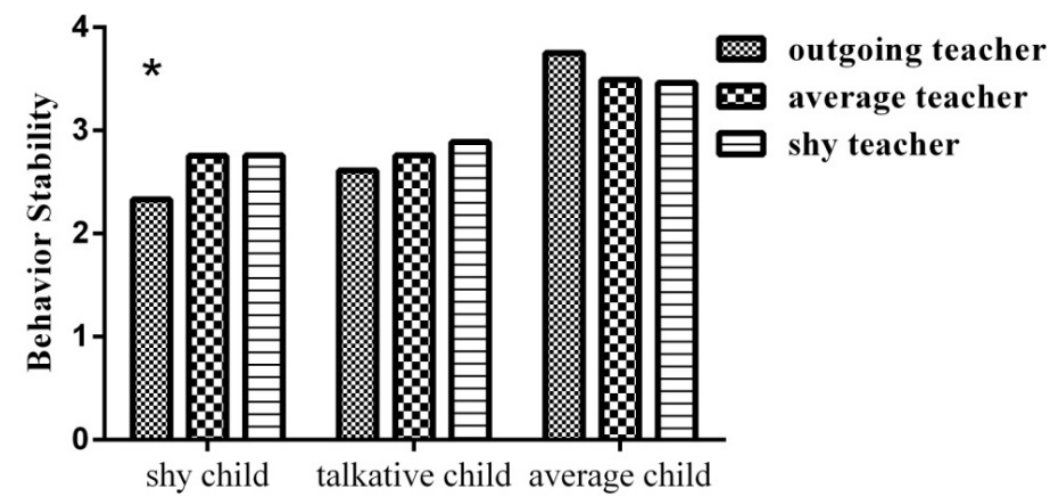

Figure 1. Child behavior by teacher shyness interaction on behavior stability.

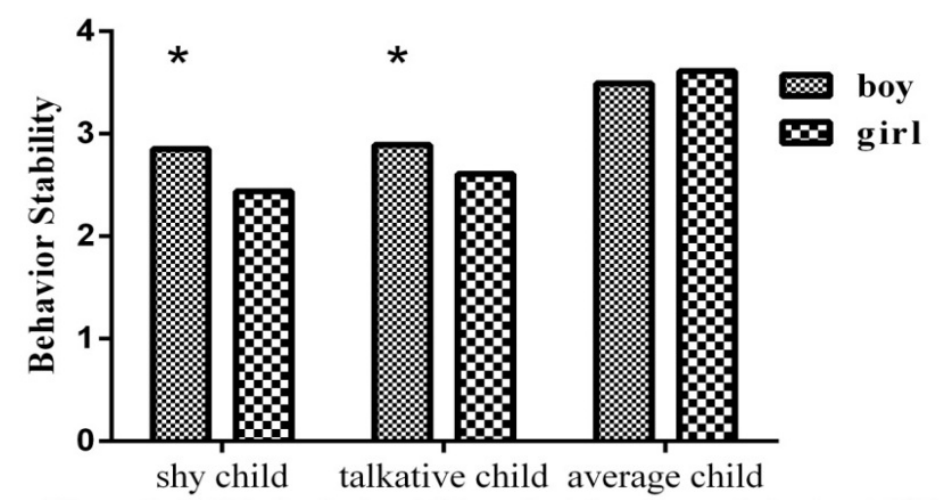

Figure 2. Child behavior by child gender interaction on behavior stability. 
Personality-situation attribution. The main effect of child behavior was significant, $F(2,420)=10.37$, $p<0.001$, partial $\eta^{2}=0.047$. There were no significant main effects of teacher shyness or child gender. As well, none of the two-way or three-way interactions were significant.

The post hoc analyses indicate that, compared with exuberant/talkative children and average children, teachers are more likely to attribute the inhibited behavior of shy/silent children as situational rather than personality (Table 1).

Academic abilities. The main effect of child behavior was significant, $F(2,420)=159.61, p<0.001$, partial $\eta^{2}=0.432$. The main effect of child gender was significant, $F(1,210)=14.36, p<0.001$, partial $\eta^{2}=0.064$. The main effect of teacher shyness was marginal significant, $F(2,210)=2.91, p=0.057$, partial $\eta^{2}=0.027$. None of the two-way or three-way interactions were significant.

The post hoc analyses indicate that, teachers' beliefs regarding the academic and verbal abilities of three types of children showed significant difference, with average child the highest, followed by the exuberant/talkative child, and the quite/shy child the lowest (see Table 1). Teachers believe that girls have better academic and verbal and academic abilities than boys.

Meanwhile, shy teachers' evaluation of children' verbal and academic abilities was significant lower than that of outgoing and average teachers.

Intelligence. The main effect of child behaviors $\left(F(2,420)=22.56, p<0.001\right.$, partial $\left.\eta^{2}=0.097\right)$, children gender $\left(F(1,210)=13.90, p<0.001\right.$, partial $\left.\eta^{2}=0.062\right)$, and teacher shyness $(F(2,210)=5.50, p<0.01)$, partial $\eta^{2}=0.050$ was significant. None of the two-way or three-way interactions were significant. The post hoc analyses indicated that, teachers' evaluation of intelligence of shy child was significantly lower than that of exuberant/talkative child and average child (see Table 1). Teachers believed that girls have higher level of intelligence than boys. Besides, shy teachers' evaluation of intelligence of children was significant lower than that of outgoing and average teachers.

Negative consequences. The main effect of child behaviors was significant $(F(2,420)=232.19, p<0.001)$, partial $\eta^{2}=0.525$. The main effect of teacher shyness was significant $(F(2,210)=3.78, p<0.05)$, partial $\eta^{2}=$ 0.035 .

The post hoc analyses indicate that, teachers' evaluation of the negative consequences of three types of behavior were significantly different from each other, with shy/quite behavior the highest negative consequence, exuberant/talkative behavior with lower negative consequence, and average behavior with the least negative consequence (Table 1). Meanwhile, as for teacher's evaluation of the negative consequences behavior on child social and academic development, shy teacher's evaluation was significantly higher than that of average teacher.

Results also revealed a significant teacher shyness $\times$ child gender interaction $(F(2,210)=3.72, p<0.05)$, partial $\eta^{2}=0.034$. None of the two-way or three-way interactions were significant. A series of $2 \times 3$ mixed repeated measure analysis of variance were conducted, with child gender (boy, girl) and teacher shyness (shy, average, and outgoing) serving as between-subject variables. Separate analyses were performed for teachers' evaluation of the negative consequences of shy and exuberant/talkative behaviors.

For the negative consequences of shy behavior, results indicated no significant main effects for child gender or teacher shyness, but there was a significant two-way interaction $(F(2,210)=5.175, p<0.01)$, partial $\eta^{2}=0.047$. For the negative consequence of exuberant/talkative behavior, results indicated no significant main 
effects or two-way interaction effect. Results from follow-up simple effects analyses indicated that outgoing teacher believed that shy/quiet behaviors have less negative consequences for boys than girls, while average teachers hold the opposite view (see Figure 3).

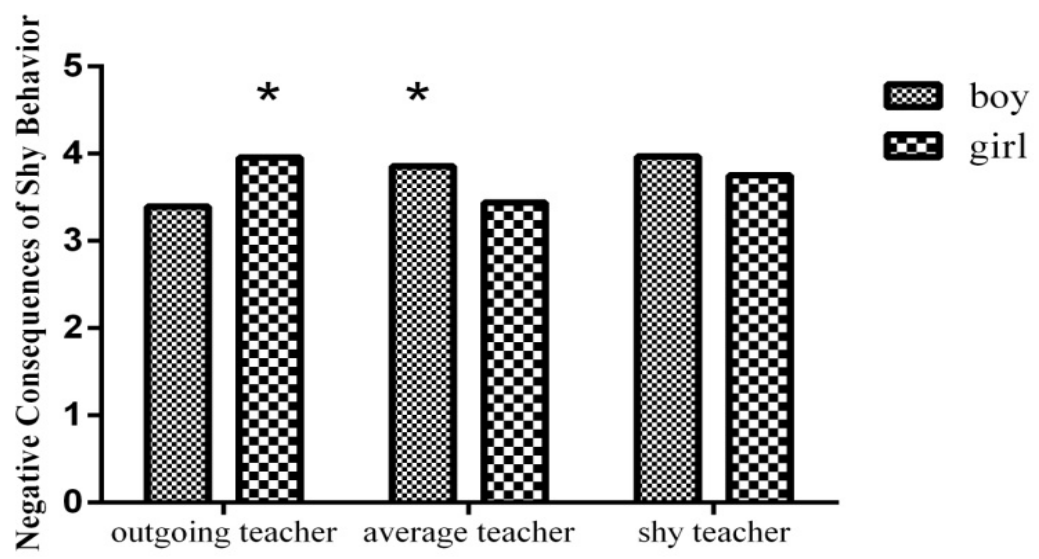

Figure 3. Teacher shyness by child gender interaction on negative consequences of shy behavioir.

\section{Teacher Strategies}

High-powered strategy. The main effect of child behavior was significant $(F(2,420)=139.245, p<$ $0.001)$, partial $\eta^{2}=0.399$; The man effect of child gender was significant $(F(1,210)=4.64, p<0.05)$, partial $\eta^{2}$ $=0.022$. There was no main significant of teacher shyness. As well, none of the two-way or three-way interactions were significant. Results from follow up post hoc analyses indicated differences between teacher's responses to the all three hypothetical children. Teachers were most likely to employ high-powered strategy to exuberant/talkative child, followed by shy child, and then the average child. Meanwhile, teachers were more likely to employ high-powered strategies for boys than girls.

Social learning strategy. The main effect of children behavior was significant $(F(2,420)=32.183, p<$ $0.001)$, partial $\eta^{2}=0.133$; and the interaction of children behavior $\times$ teacher shyness was significant $(F(4,420)=$ $3.108, p<0.05)$, partial $\eta^{2}=0.029$. There were no significant main effects of other variables. As well, none of the two-way or three-way interactions were significant. Results of post hoc analyses indicated differences between teacher responses to the behaviors of all three vignettes. Teachers were likely to employ social learning strategies in response to the behaviors of the shy child, followed by the exuberant and talkative child, and then the average child (see Table 1).

With regard to the two-way child behavior $\times$ teacher shyness interaction, results from follow-up simple effects analyses (see Figure 4) indicated that, teachers with different levels showed no significant difference in their likelihoods to employ social learning strategy to both shy children and exuberant/ talkative children. However, their likelihoods to apply such strategy to average children were significantly different $(F(2,213)=$ $3.67, p<0.05)$. That is, compared with shy and outgoing teachers, average teachers were more likely to employ social learning strategy to average children.

Peer-focused strategy. The main effect of children behavior was significant $(F(2,420)=55.22, p<$ $0.001)$, partial $\eta^{2}=0.208$. The main effect of teacher shyness was marginal significant $(F(2,210)=2.96, p=$ $0.054)$, partial $\eta^{2}=0.027$. There was no significant main effect of child gender or two-way or three-way interactions. Results of post hoc analyses indicated significant differences between teacher's peer-focused 
strategies to all three vignettes. Teachers were most likely to employ peer-focused in response to the behaviors of shy child, followed by exuberant/talkative child, and then average child (see Table 1). Meanwhile, the level of shy teachers' employing peer-focused strategy towards child is lower than that of outgoing and average teachers.

Indirect strategy. The main effect of children behavior was significant $(F(2,420)=11.25, p<0.001)$, partial $\eta^{2}=0.051$. The main effect of teacher shyness was marginal significant $(F(2,210)=3.02, p=0.051)$, partial $\eta^{2}=0.028$. There was no significant main effect of child gender or two-way or three-way interactions. The post hoc analyses indicate that, teachers were most likely to employ indirect in response to the behaviors of the average child, followed by the shy child, and then the exuberant/talkative child (Table 1). Meanwhile, shy teachers were more likely to employ indirect strategies to children than outgoing teachers.

Report strategy. The main effect of children behavior was marginal significant $(F(2,420)=2.88, p=$ $0.057)$, partial $\eta^{2}=0.014$. There was no other significant main effect. None of the two-way or three-way interactions were significant. Results of post hoc analyses indicated teachers are more likely to employ report strategy to shy child than talkative child and average child (see Table 1).

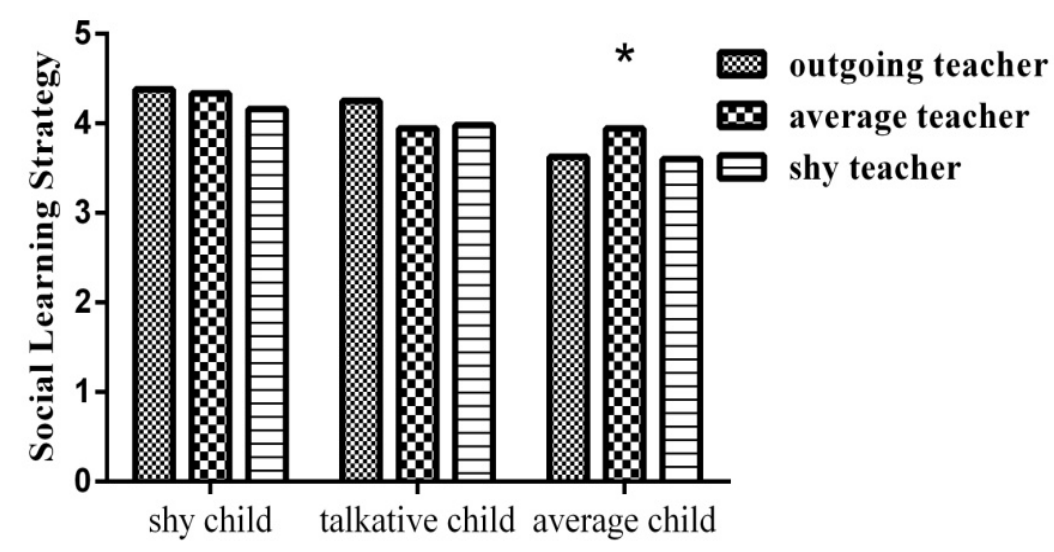

Figure 4. Child behavior by teacher shyness interaction on social learning strategy.

\section{Discussion}

\section{Influence of Behavior Patterns of Children}

In term of teacher beliefs, the current study found that teacher hold the view that shy/quiet children had the poorest verbal skills and the lowest academic performance in their class among the three hypothetical children. This result is consistent with previous research indicating that shy children got lower scores in tests of language abilities and may also experience other academic difficulties (Evans, 2010). However, the poorer language and academic performance of shy children may result from their temperamental characteristics (e.g., easy to get anxious), rather than the assumption that shy children have lower intelligence than other children. Despite these concerns, teachers rated shy children as being the least intelligent. In view of the fact that teacher's expectations have significant effects on both child behavior and school satisfaction (Fan \& Jin, 2008), it is necessary to take an in-depth look at whether teachers' lower expectation of shy children has some influence on shy children's poorer verbal skills and worse academic performance. At the same time, teachers commonly think that shyness has deep negative effect on children's academic and social skills. Teachers are more likely to 
report children's shy/quiet behaviors to others (e.g., principal, parents). Our findings support the results of a growing number of previous studies which indicated that teachers increasingly pay attention to shy and quiet children (Arbeau \& Coplan, 2007; Coplan et al., 2011).

Literature of parenting studies suggested that parents tend to be developmental optimists. They intend to attribute more positive child behaviors to internal causes (i.e., trait like, more stable) and negative behaviors to external causes (i.e., due to situation, more transient) (Coplan, Hastings, Lagacé-Séguin, \& Moulton, 2002). The current study found that kindergarten teachers also have this tendency. In term of teacher beliefs, they tend to view shy/quiet and exuberant/talkative behaviors as unstable features, and they attribute the shy/quiet behaviors of children as more due to situation (i.e., less due to the personality). Holding this belief is beneficial for teachers to take measures to guide and improve children's behaviors.

It is noteworthy that teachers thought that exuberant/talkative children may display lower verbal and academic ability than average children (although higher than shy/quiet children). They also think exuberant/talkative behaviors have great negative effect on children's social and academic developments. The result confirmed the finding that, despite verbal participation is generally considered as an important component of classroom learning, excessive exuberant/talkative behaviors are viewed as negative (Stifter, Putnam, \& Jahromi, 2008). In term of strategy, teachers were more likely to employ high-powered strategies towards children with exuberant/talkative behaviors.

In term of teacher strategy, teachers were more likely to employ indirect strategies to shy children than outgoing child. And teachers were most likely to employ social learning strategies and peer-focused strategies in response to the behaviors of the shy/quiet child. These practices are highly recommended in literatures on shy children intervention (Wu et al., 2014). Empirical research also suggested that early intervention approaches for shy children that involve peers showed promising effects (Coplan, Schneider, Matheson, \& Graham, 2010).

\section{Influence of Child Gender and Teacher Shyness}

The shyness level of teachers is significantly related to their strategies and beliefs towards students. In term of teacher beliefs, current study found that, compared with outgoing and average teachers, shy teachers rate shy children as less likely to perform well academically and as being less intelligent than average and exuberant children. Meanwhile, compared with average teachers, shy teachers believe that children's behaviors may have more negative effect on children's development.

With regard to strategies, compared with outgoing and average teachers, shy teachers are less likely to apply peer-focused strategies. Shy teachers tend to apply more indirect strategies than outgoing teachers. Shy individual shares a personality typically characterized by self-consciousness and a lack of self-confidence (Chen, Gao, \& Wu, 2013), which may result in teachers' negative evaluation of child and their preference of applying indirect strategies.

Child gender also affects teachers' strategies and beliefs. In term of beliefs, teachers rated that girls have higher intelligence and better verbal and academic abilities. These findings are consistent with previous study on teacher and parents' evaluation of kindergarten children which indicated that girls possess higher social and academic abilities than boys (Abdi, 2010). Meanwhile, teachers believed that the behavior of boys was more stable and not easy to be changed than girls'. Corresponding to this result, teachers reported that they are more likely to employ high-powered strategies in response to boys. 


\section{Interaction of Relevant Factors}

The current study indicated that teachers' strategies and beliefs are also affected by the interaction between child gender, child behavior and teacher shyness. In term of beliefs, teacher believe that the shy/quiet and exuberant/talkative behaviors of boys are more stable than girls. In other words, the negative behaviors of boys are more difficulty to change than girls'. Meanwhile, with regard to the stability of shy/quiet behaviors, outgoing teachers reported significant lower stability than average teachers and shy teachers. That is to say, outgoing teachers are more likely to consider shy/quiet behaviors as changeable. Teachers' evaluation of the negative effects of shy/quiet behaviors on children's social interaction and academic development is influenced by the interaction of teacher shyness and child gender. Average teachers reported that girls are less affected by negative effect of shy/quiet behaviors than boys. This is consistent with previous research which indicated that parents and peers appear to respond more negatively to shy boys than shy girls (Wu et al., 2014). However, it should be noted that shy teachers think that shyness has more negative influence on girls than boys.

With regard to strategies, current study indicated that the levels of employing social learning strategies towards average child of shy and outgoing teachers are lower than that of average teachers. However, there is no significant differences in levels of employing such strategy towards shy/quiet and exuberant/talkative child among three kinds of teachers.

The present study examined preschool teachers' beliefs and strategies regarding hypothetical shy (i.e., quiet), exuberant (i.e., overly talkative), and average (i.e., typical) children. And we also explored whether these strategies and beliefs varied as a function of the gender of the hypothetical child as well as teachers' own shyness, which has certain theoretical significance and practical value to future research and application. However, certain limitations should be noted. To begin with, the representativeness of the present sample needs to be improved. The participants in current study were predominantly young and inexperienced teachers. With the increase of teachers' teaching experience and the improvement of their professional quality, it is possible that teachers may change their belief and attitude towards child. Besides, teachers' notice of the behavioral problems does not represent that they would address these problems in real-world contexts. For example, research indicated that teachers are more likely to focus on child behaviors that may disrupt their teaching goals, such as more aggressive, defiant, and off-task behaviors (Nucci \& Turiel, 2009). In addition, teachers reported that, compared with internalizing problems, they are more concerned about children's externalizing problems (Loades \& Mastroyannopoulou, 2010). Thus, in future research, applying behavior observation in actual classroom should be a promising way of investigating teachers' strategies towards different children.

\section{References}

Abdi, B. (2010). Gender differences in social skills, problem behaviours and academic competence of Iranian kindergarten children based on their parent and teacher ratings. Procedia-Social and Behavioral Sciences, 5, 1175-1179.

Arbeau, K. A., \& Coplan, R. J. (2007). Kindergarten teachers' beliefs and responses to hypothetical prosocial, asocial, and antisocial children. Merrill-Palmer Quarterly, 53(2), 291-318.

Cheek, J. M., \& Buss, A. H. (1999). Shyness scale. In X. Wang, X. Wang, \& H. Ma (Eds.), Manual for mental health assessment scale (pp. 246-248). Beijing: Chinese Mental Health Journal Press.

Chen, X., DeSouza, A. T., Chen, H., \& Wang, L. (2006). Reticent behavior and experiences in peer interactions in Chinese and Canadian children. Developmental Psychology, 42(4), 656-665.

Chen, Y. M., Gao, F. Q., \& Wu, Y. P. (2013). Shyness: Haixiu or Xiuqie. Journal of Psychological Science, 36(2), 501-505.

Coplan, R. J., \& Armer, M. (2007). A "Multitude" of Solitude: A closer look at social withdrawal and nonsocial play in early childhood. Child Development Perspectives, 1(1), 26-32. doi:10.1111/j.1750-8606.2007.00006.x. 
Coplan, R. J., Hastings, P. D., Lagacé-Séguin, D. G., \& Moulton, C. E. (2002). Authoritative and authoritarian mothers' parenting goals, attributions, and emotions across different childrearing contexts. Parenting: Science and Practice, 2(1), 1-26.

Coplan, R. J., Hughes, K., Bosacki, S., \& Rose-Krasnor, L. (2011). Is silence golden? Elementary school teachers' strategies and beliefs regarding hypothetical shy/quiet and exuberant/talkative children. Journal of Educational Psychology, 103(4), 939-951.

Coplan, R. J., Schneider, B. H., Matheson, A., \& Graham, A. (2010). "Play skills" for shy children: Development of a social skills facilitated play early intervention program for extremely inhibited preschoolers. Infant and Child Development, 19(3), 223-237.

Evans, M. A. (1996). Reticent primary grade children and their more talkative peers: Verbal, nonverbal, and self-concept characteristics. Journal of Educational Psychology, 88(4), 739-749.

Evans, M. A. (2010). Language performance, academic performance, and signs of shyness: A comprehensive review. In K. H. Rubin, \& R. J. Coplan (Eds.), The development of shyness and social withdrawal (pp. 179-212). New York, N.Y.: Guilford Press.

Fan, L., \& Jin, S. (2008). Influence of teacher expectations on psychological characteristic in junior middle school students. Psychological Development and Education, 3, 48-52.

Fox, N. A., Henderson, H. A., Rubin, K. H., Calkins, S. D., \& Schmidt, L. A. (2001). Continuity and discontinuity of behavioral inhibition and exuberance: Psychophysiological and behavioral influences across the first four years of life. Child Development, 72(1), 1-21.

Hughes, K., \& Coplan, R. J. (2010). Exploring processes linking shyness and academic achievement in childhood. School Psychology Quarterly, 25(4), 213-222.

Loades, M. E., \& Mastroyannopoulou, K. (2010). Teachers' recognition of children's mental health problems. Child and Adolescent Mental Health, 15(3), 150-156.

McAuliffe, M. D., Hubbard, J. A., \& Romano, L. J. (2009). The role of teacher cognition and behavior in children's peer relations. Journal of Abnormal Child Psychology, 37(5), 665-677.

Nucci, L., \& Turiel, E. (2009). Capturing the complexity of moral development and education. Mind, Brain, and Education, 3(3), 151-159.

Pajares, M. F. (1992). Teachers' beliefs and educational research: Cleaning up a messy construct. Review of Educational Research, 62(3), 307-332.

Rudasill, K. M., \& Rimm-Kaufman, S. E. (2009). Teacher-child relationship quality: The roles of child temperament and teacher-child interactions. Early Childhood Research Quarterly, 24(2), 107-120.

Stifter, C. A., Putnam, S., \& Jahromi, L. (2008). Exuberant and inhibited toddlers: Stability of temperament and risk for problem behavior. Development and Psychopathology, 20(2), 401-421.

Thijs, J. T., Koomen, H. M. Y., \& Van Der Leij, A. (2006). Teachers' self-reported pedagogical practices toward socially inhibited, hyperactive, and average children. Psychology in the Schools, 43(5), 635-651.

Valiente, C., Swanson, J., \& Lemery-Chalfant, K. (2012). Kindergartners' temperament, classroom engagement, and student-teacher relationship: Moderation by effortful control. Social Development, 21(3), 558-576.

Wu, Y., Chen, Y., Yu, Y., Wu, J., \& Gao, F. (2014). Review on the maladjustment of shy preschool children and its interventions. Chinese Journal of Child Health Care, 22(2), 164-166.

Wu, Y., Wu, J., Chen, Y., Han, L., Han, P., Wang, P., \& Gao, F. (2014). Shyness and school adjustment among Chinese preschool children: examining the moderating effect of gender and teacher-child relationship. Early Education \& Development. doi: 10.1080/10409289.2015.970503

Zhang, L. (2007). Do personality traits make a difference in teaching styles among Chinese high school teachers? Personality and Individual Differences, 43(4), 669-679. 